\title{
The Crystal and Molecular Structure of 4-Formylimidazoline-2-thione
}

\author{
By A. Conde, E. Moreno And R. MÁrquez \\ Departamento de Optica y Sección de Física del Departamento de Investigaciones Física y Químicas (Centro \\ Coordinado del CSIC), Universidad de Sevilla, Spain
}

(Received 20 July 1976; accepted 20 August 1976)

\begin{abstract}
The title compound is monoclinic, space group $P 2_{1} / c$, with $a=4.020(4), b=21.491(3), c=7.410(4) \AA$, $\beta=124 \cdot 1(5)^{\circ}, Z=4$. The structure was solved by Patterson-function and heavy-atom methods from diffractometer X-ray data. The final $R$ value is $0 \cdot 040$. All the atoms lie approximately on the least-squares plane of the imidazoline ring. The molecules related by the glide plane are linked by $\mathrm{N}-\mathrm{H} \cdots \mathrm{O}$ hydrogen bonds $(2 \cdot 840 \AA)$ to form a chain along $\mathbf{c}$. The chains are held together by $\mathrm{N}-\mathrm{H} \cdots \mathrm{S}$ hydrogen bonds $(3 \cdot 260 \AA)$ between the molecules related by an inversion centre.
\end{abstract}

\section{Introduction}

The title compound $\left(\mathrm{H}_{4} \mathrm{C}_{4} \mathrm{~N}_{2} \mathrm{OS}\right)$ is the basis of a series of derivative carbohydrates synthesized in the Departamento de Quimica Orgánica of this University and the $\mathrm{X}$-ray structural analysis was suggested in order to establish the details of its molecular conformation in the crystalline state.<smiles>O=Cc1c[nH]c(=S)[nH]1</smiles>

This work forms part of a continuing investigation on the conformational aspects of glucimidazoles and imidazole C-nucleosides. Other structural analyses have been carried out in our laboratory recently by Conde, Moreno \& Márquez (1975), Vega, HernándezMontis \& López-Castro (1976), Jiménez-Garay, López-Castro \& Márquez (1976). The aim of these studies is to elucidate the reaction mechanisms involved in the syntheses of the derivatives.

\section{Experimental}

Single crystals of the compounds were prepared and kindly supplied by Professor J. Fernández-Bolaños. The crystals are colourless prisms elongated along $\mathbf{c}$.

Table 1. Crystal data

$$
\begin{aligned}
a & =4.020(4) \AA \\
b & =21 \cdot 491(3) \\
c & =7.410(4) \\
\beta & =124 \cdot 1(5)^{\circ} \\
V & =530.07 \AA^{3}
\end{aligned}
$$

Preliminary rotation and Weissenberg photographs indicated monoclinic symmetry. The conditions for reflexion were observed to be: $0 k 0, k=2 n$ and $h 0 l$, $l=2 n$ and the space group consistent with these observations is $P 2_{1} / c$.

The unit-cell parameters were determined by a leastsquares method from 25 accurate $2 \theta$ values measured on an automatic four-circle diffractometer. The resulting values with other crystal data are summarized in Table 1.

Intensity data were collected by the $\omega-2 \theta$ scan method on a Philips automated four-circle diffractometer with graphite-monochromated Mo $K \alpha$ radiation $(\lambda=0.7107 \AA)$. Reflexions were collected in the range $2^{\circ}<\theta<30^{\circ}$. Three reflexions were remeasured after every 50 reflexions during the data collection and the variation in intensity was observed to be less than $1.5 \%$ of the mean intensity.

The intensities of 1676 independent reflexions were measured and 776 of these reflexions with $I<2 \sigma(I)$ were considered as unobserved and assigned zero weight throughout the refinement process. The data were corrected for Lorentz-polarization effects in the usual way but not for absorption $(\mu R<0 \cdot 1)$.

\section{Solution and refinement of the structure}

The solution of the structure was not straightforward and both direct methods and the Patterson method were applied. Initially some trials with the MULTAN program were intended but from the convergence mapping a successful starting set was not obtained. Then a three-dimensional Patterson synthesis was performed and the position of the $\mathrm{S}$ atom could be derived. All the non-hydrogen atoms were located from a three-dimensional electron-density synthesis in which the phase angles were determined from the $S$ atom position. The isotropic temperature factor $\exp \left(-B \sin ^{2} \theta / \lambda^{2}\right)$ with $B$ 
$=2.5 \AA^{2}$ was used in calculating structure factors; the $R$ value was $0 \cdot 18$.

Refinement was by full-matrix least squares minimizing $\Sigma w|| F_{o}|-| F_{c}||^{2}$ with $w=1 / \sigma_{F_{o}}^{2}$. A least-squares program (Busing, Martin \& Levy, 1964) was used. Heavy-atom coordinates, isotropic thermal parameters and a scale factor were refined to an $R$ of 0.07 . Two cycles of anisotropic refinement were performed and the $R$ value dropped to 0.05 . At this stage a difference Fourier synthesis calculated with $\sin \theta$ up to 0.35 revealed the positions of the four $\mathrm{H}$ atoms. For two cycles the scale factor, the atomic coordinates for all atoms and the anisotropic thermal parameters for the heavy atoms ( 85 parameters in all) were varied. For $\mathrm{H}$ atoms, the isotropic thermal parameters are those of the bonded atom. The final agreement index, $R_{w^{\prime}}=$ $\Sigma|| F_{o}|-| F_{c}|| / \Sigma\left|F_{o}\right|$, was 0.040 for observed and 0.047 for all reflexions.

The atomic scattering factors for $\mathrm{S}, \mathrm{O}, \mathrm{N}$ and $\mathrm{C}$ were taken from Cromer \& Mann (1968) and for $\mathrm{H}$ from International Tables for X-ray Crystallography (1962).

The atomic positional and thermal parameters from the final least-squares cycle are given in Table 2.* The standard deviations were determined from the diagonal elements of the inverse matrix in the least-squares procedure.

\section{Molecular structure and packing}

\section{(i) Molecular geometry}

The bond lengths and valency angles are shown in Fig. 1. The observed values for the bond distances

* A list of structure factors has been deposited with the British Library Lending Division as Supplementary Publication No. SUP 32109 (9 pp.). Copies may be obtained through The Executive Secretary, International Union of Crystallography, 13 White Friars, Chester CH1 1 NZ, England.
$\mathrm{S}-\mathrm{C}(1), \mathrm{C}(1)-\mathrm{N}(1)$ and $\mathrm{C}(1)-\mathrm{N}(2)$ are in agreement with the canonical resonance forms of the thiourea system and this is a normal feature of these compounds (Pérez-Garrido, López-Castro \& Márquez, 1973; Jiménez-Garay, López-Castro \& Márquez, 1974; Pérez-Garrido, Conde \& Márquez, 1974; Vega, Hernández-Montis \& Lopez-Castro, 1976). The $\mathrm{N}(1)-\mathrm{C}(2)$ and $\mathrm{N}(2)-\mathrm{C}(3)$ distances are longer than the aromatic $\mathrm{C}-\mathrm{N}$ length but agree well with the weighted average in the above imidazoline derivatives. The $C(2)-C(3)$ distance agrees with the mean value, 1.357 (1) $\AA$, observed in imidazoline derivatives. Further comparisons are available for imidazole derivative geometries (Guggenberger, 1976; James \& Matsushima, 1976). Valency angles in the ring may be compared with the values observed in analogous compounds.

The $\mathrm{C}(2)-\mathrm{C}(4)$ bond length of $1.411(5) \AA$ is shorter

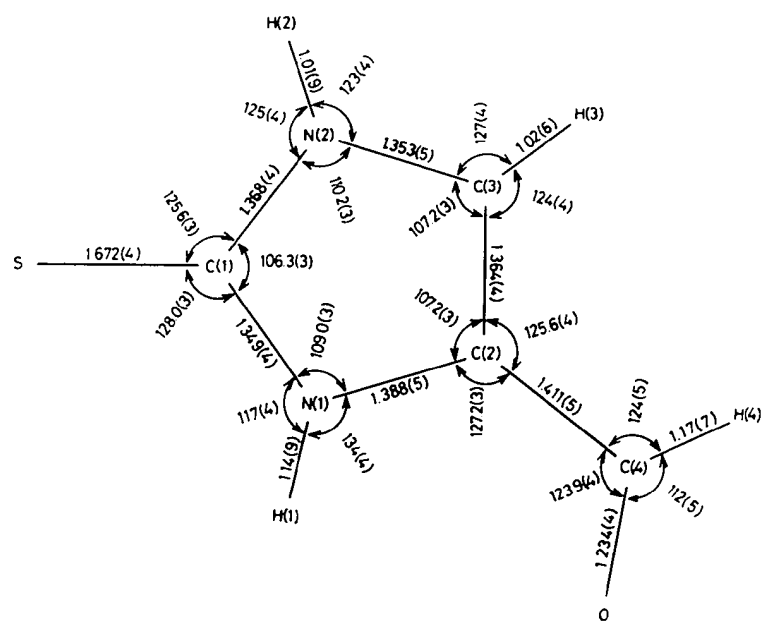

Fig. 1. Bond lengths $(\AA)$ and angles $\left({ }^{\circ}\right)$.

Table 2. Final fractional coordinates $\left(\times 10^{4}\right.$ for non-hydrogen atoms, $\times 10^{3}$ for hydrogen $)$ and temperature factors $\left(\beta_{i j} \times 10^{4}\right)$ with e.s.d.'s in parentheses

\begin{tabular}{|c|c|c|c|c|c|c|c|c|c|}
\hline & $x$ & $y$ & $z$ & $\beta_{11}$ & $\beta_{22}$ & $\beta_{33}$ & $\beta_{12}$ & $\beta_{13}$ & $\beta_{23}$ \\
\hline$S$ & $12335(3)$ & $623(1)$ & $7855(2)$ & $493(9)$ & $14(0)$ & $143(3)$ & $14(1)$ & $73(4)$ & $-4(1)$ \\
\hline $\mathrm{O}$ & $1019(7)$ & $2559(1)$ & $3650(4)$ & $924(32)$ & $14(1)$ & $251(12)$ & $32(5)$ & $187(16)$ & $10(2)$ \\
\hline $\mathrm{N}(1)$ & $6539(9)$ & $1494(1)$ & $5528(5)$ & $590(32)$ & $10(1)$ & $135(10)$ & $2(4)$ & $133(16)$ & $1(2)$ \\
\hline $\mathrm{N}(2)$ & $5500(9)$ & $623(1)$ & $3795(5)$ & $652(34)$ & $13(1)$ & $150(11)$ & $-9(5)$ & $152(16)$ & $-8(3)$ \\
\hline$C(1)$ & $8111(10)$ & $924(1)$ & $5716(6)$ & $532(39)$ & $9(1)$ & $128(11)$ & $-10(5)$ & $144(18)$ & $-5(3)$ \\
\hline $\mathrm{C}(2)$ & 2949 (11) & $1546(1)$ & $3496(6)$ & $555(39)$ & $12(1)$ & $145(12)$ & $0(5)$ & $139(18)$ & $4(3)$ \\
\hline$C(3)$ & $2345(12)$ & 995 (1) & $2438(6)$ & $526(39)$ & $17(1)$ & $169(14)$ & $14(6)$ & $149(20)$ & $6(3)$ \\
\hline \multirow[t]{2}{*}{ C(4) } & $372(12)$ & $2066(1)$ & $2646(7)$ & $777(46)$ & $12(1)$ & $211(15)$ & $19(6)$ & $238(22)$ & $14(3)$ \\
\hline & $x$ & $y$ & $z$ & $B\left(\AA^{2}\right)$ & & $x$ & $y$ & $z$ & $B\left(\AA^{2}\right)$ \\
\hline$H(1)$ & $827(15)$ & $182(5)$ & $701(10)$ & $2 \cdot 3$ & $\mathrm{H}(3)$ & $17(16)$ & $92(4)$ & $84(9)$ & 3.4 \\
\hline $\mathrm{H}(2)$ & $594(16)$ & $20(5)$ & $337(9)$ & $2 \cdot 6$ & $\mathrm{H}(4)$ & $-271(17)$ & $208(7)$ & $93(12)$ & $2 \cdot 5$ \\
\hline
\end{tabular}


than that expected for a $\mathrm{C}-\mathrm{C}$ 'single' bond. This shortening is consistent with the partial double-bond character expected in the presence of a $\mathrm{C}$ to $\mathrm{O}$ double bond and a $\mathrm{C}$ to $\mathrm{C}$ double bond.

Table 3. Least-squares plane in the molecule

Equation of plane in the standard orthogonal system $0.8555 x+0.3529 y-0.3790 z=0.1284$

Deviations $\left(\times 10^{3} \AA\right)$ from the plane

$\begin{array}{lrlrlr}\mathrm{C}(1) & -1 & \mathrm{C}(3) & -2 & { }^{*} \mathrm{H}(1) & -30 \\ \mathrm{~N}(1) & 0 & { }^{*} \mathrm{~S} & -35 & { }^{*} \mathrm{H}(2) & 80 \\ \mathrm{~N}(2) & 2 & { }^{*} \mathrm{C}(4) & 9 & { }^{*} \mathrm{H}(3) & 139 \\ \mathrm{C}(2) & 1 & { }^{*} \mathrm{O} & 15 & { }^{*} \mathrm{H}(4) & -31\end{array}$

* Atom not included in calculating the plane.

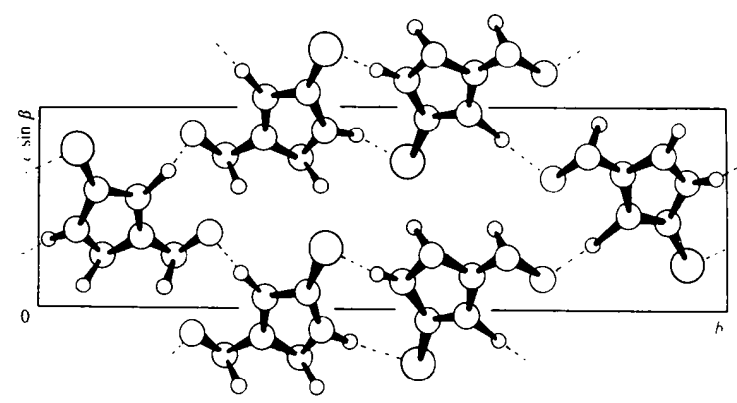

Fig. 2. A view along [100] of the contents of the cell.

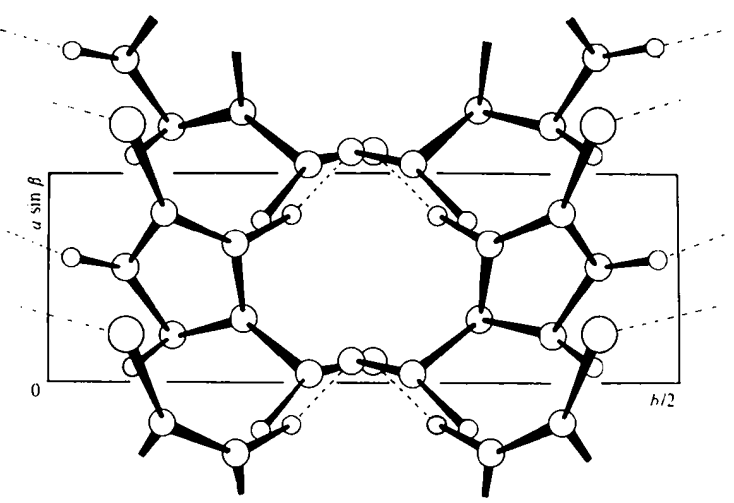

Fig. 3. A partial view along [001] of the structure.
The data for the least-squares plane through the imidazoline ring are given in Table 3. The ring is planar within experimental error and all atoms lie almost in the least-squares plane of the ring. The largest displacement is $0.035 \AA$ for non-hydrogen and $0.14 \AA$ for $\mathrm{H}$ atoms.

\section{(ii) Molecular packing}

Fig. 2 shows a view along [100] of the contents of the cell and Fig. 3 shows a partial view along [001]. The most important features of the crystal packing are hydrogen bonding, the detailed geometry of which is shown in Table 4. The molecules related by the $c$ glide plane form chains in one dimension by $\mathrm{N}-\mathrm{H} \cdots \mathrm{O}$ hydrogen bonds. The chains are linked by $\mathrm{N}-\mathrm{H} \ldots \mathrm{S}$ hydrogen bonds between molecules related by an inversion centre.

Some intermolecular contacts shorter than the van der Waals radii also contribute to the crystal cohesion. The most important feature is the stacking along a. Short contacts are shown in Table 5.

Computations were carried out on a DCT 2000 terminal of the Computing Centre of this University, connected to a Univac 1108 computer.

The authors thank Professor J. Fernàndez-Bolaños for supplying the crystals, and the laboratory staff of the X-ray department of the Instituto Rocasolano del CSIC (Madrid) for the use of a Philips diffractometer, especially Dr Cano for collecting the data.

Table 5. Short intermolecular distances $(\AA)$ (non-hydrogen atoms)

$\begin{array}{ll}\text { S-C }(1)^{\mathrm{i}} & 3 \cdot 528(5) \\ \text { S-C }(3)^{\mathrm{ii}} & 3 \cdot 486(4) \\ \text { O-C }(4)^{\mathrm{iii}} & 3 \cdot 218(6) \\ \mathrm{C}(1)-C(2)^{\mathrm{i}} & 3 \cdot 444(6) \\ \mathrm{C}(1)-C(3)^{\mathrm{i}} & 3 \cdot 668(7) \\ C(2)-C(4)^{\mathrm{i}} & 3 \cdot 558(7)\end{array}$

Symmetry code: (i) $1+x, y, z$; (ii) $1+x, y, 1+z$; (iii) $x, \frac{1}{2}-y$, $\frac{1}{2}+z$.

Table 4. Geometry of hydrogen bonding

$\begin{array}{ccccc}A \cdots \mathrm{H}-B & A \cdots B(\AA) & A \cdots \mathrm{H}(\AA) & A \cdots \mathrm{H}-B\left({ }^{\circ}\right) & \mathrm{H}-B \cdots A\left(^{\circ}\right) \\ \mathrm{S} \cdots \mathrm{H}(2)-\mathrm{N}(2) & 3 \cdot 260(3) & 2 \cdot 27(9) & 167(6) & 9(4) \\ \mathrm{O} \cdots \mathrm{H}(1)-\mathrm{N}(1) & 2 \cdot 840(3) & 1.73(9) & 161(7) & 11(4)\end{array}$

Symmetry code: (i) $2-x,-y,-z$; (ii) $-1+x, \frac{1}{2}-y,-\frac{1}{2}+z$. 


\section{References}

Busing, W. R., Martin, K. O. \& Levy, H. A. (1964). ORFLS. Oak Ridge National Laboratory Report ORNLTM-305.

Conde, A., Moreno, E. \& Márquez, R. (1975). Acta Cryst. B31, 648-652.

Cromer, D. T. \& MANN, J. B. (1968). Acta Cryst. A24, $321-324$.

Guggenberger, L. J. (1976). Acta Cryst. B32, 13-19.

International Tables for X-ray Crystallography (1962). Vol. III. Birmingham: Kynoch Press.

Acta Cryst. (1977). B33, 797-800
James, M. N. G. \& Matsushima, M. (1976). Acta Cryst. B32, 1708-1713.

JimÉnez-Garay, R., López-CaStro, A. \& MÁRquez, R. (1974). Acta Cryst. B30, 1801-1805.

JimÉnez-Garay, R., López-CASTro, A. \& MÁrquez, R. (1976). Acta Cryst. B32, 1367-1371.

Pérez-Garrido, S., Conde, A. \& MÁrquez, R. (1974). Acta Cryst. B30, 2348-2352.

Pérez-Garrido, S., López-Castro, A. \& Márquez, R. (1973). An. Fís. 69, 179-188.

VEga, R., Hernández-Montis, V. \& López-Castro, A. (1976). Acta Cryst. B32, 1363-1366.

\title{
$\alpha$-Hydroxyphenylacetic Acid: A Redetermination
}

\author{
By Kwo-Tsair WeI and Donald L. WaRd \\ Department of Chemistry, Michigan State University, East Lansing, Michigan 48824, USA
}

(Received 17 May 1976; accepted 20 August 1976)

\begin{abstract}
Crystals of $\mathrm{C}_{8} \mathrm{H}_{8} \mathrm{O}_{3}$ (also commonly known as phenylglycolic acid and as mandelic acid) are orthorhombic, Pbca, $a=9.669$ (2), $b=16.183$ (3), $c=9.953(2) \AA, 25^{\circ} \mathrm{C}, M_{r}=152 \cdot 15, Z=8, D_{m}=1.300(2), D_{x}=$ $1.298 \mathrm{~g} \mathrm{~cm}^{-3}$; the material was recrystallized from aqueous solutions. The structure exhibits an extensive hydrogen-bonding network in two dimensions (parallel to the ac plane) involving the carboxyl and hydroxyl $\mathrm{O}$ and $\mathrm{H}$ atoms.
\end{abstract}

\section{Introduction}

Single crystals of the title compound are currently being studied by ESR techniques (Rogers \& Waller, 1975). The crystal and molecular structure determination was undertaken to provide a correlation of its structure with the ESR parameters of radiation-produced radicals and to reveal the hydrogen-bonding network.

The diffraction conditions $h 0 l: l=2 n, 0 k l: k=2 n$, and $h k 0: h=2 n$, the absence of other unrelated conditions, and the orthorhombic symmetry establish the space group as $\mathrm{Pbca}$. Diffraction data were measured at $25^{\circ} \mathrm{C}$ with a Picker FACS-I automatic diffractometer using $\mathrm{Zr}$-filtered Mo $K \alpha$ radiation. The cell parameters were determined by a least-squares fit to the angular settings $(2 \theta, \omega, \chi, \varphi)$ of 12 reflections in the range $35^{\circ} \leq 2 \theta \leq 39^{\circ}$ for which the $\alpha_{1}, \alpha_{2}$ doublet was clearly resolved $\left[\lambda\right.$ for Mo $\left.K \alpha_{1}=0.70926 \AA\right]$. The density was determined by flotation in a mixture of 1 bromobutane, tetrachloroethylene, and 1,2-dichloroethane. The 1383 unique reflections [including 604 'unobserved' for which $I<\sigma(I)]$ were collected for $2 \theta \leq 50^{\circ}$ using the $\theta-2 \theta$ scan method: scan speed of $2^{\circ}(2 \theta) \mathrm{min}^{-1} ; 10 \mathrm{~s}$ backgrounds; scan ranges of $1.50^{\circ}$

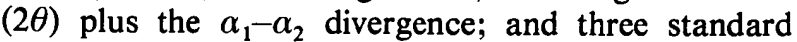
reflections measured after every 50 data were used to scale the data. The data were reduced and standard deviations calculated as a function of counting statistics as reported previously (Wei \& Ward, 1976). The least-squares refinement weights were calculated from the standard deviations of the structure factors by $1 /\left[\sigma^{2}+(0.02 F)^{2}\right]$; an absorption correction $[\mu$ for Mo $\left.K \alpha=0.61 \mathrm{~cm}^{-1}\right]$ was not applied and an extinction correction was applied to the data by $\mathrm{FOBS}_{\mathrm{cor}}=(1.0$ $+E F \times$ RAWI) $\times$ FOBS, where RAWI is the raw intensity and the final EF $=1.2 \times 10^{-6}$. The extinction factor was not included in the least-squares refinement but was adjusted graphically between the final three cycles of least squares.

The crystal structure was solved with the directmethods program MULTAN (Germain, Main \& Woolfson, 1971). Other programs used in this study include ORTEP (Johnson, 1965), the entire system of Zalkin's (1974) programs and programs written and/or modified locally. A CDC 6500 computer was used.

The structure was refined by full-matrix least squares \{779 observed data $[I \geq \sigma(I)], 131$ atomic parameters and one scale factor $\}$ to $R_{1}=\left(\Sigma\left|F_{o}-F_{c}\right|\right) / \Sigma F_{o}=$ $0.087, R_{2}=\left\{\left[\Sigma w\left(\mathrm{~F}_{o}-F_{c}\right)^{2}\right] / \Sigma w\left(F_{o}\right)^{2}\right\}^{1 / 2}=0.066, R_{1}=$ 0.163 including the 604 zero-weighted data for which $I \leq \sigma(I)$; the standard deviation of an observation of unit weight $=1.044$; the parameters are listed in Table 1. The average and maximum shift-to-error ratios for the last cycle of least-squares refinement were 